\title{
32. SOBRE ASPLENIUM $X$ PROTOMAJORICUM PANGUA Y PRADA Y A. X PROTOMAJORICUM PÉREZ-CARRO Y FERNÁNDEZ ARECES
}

\author{
A. Enrique SALVO
}

Palabras clave. Pteridófitos, Asplenium, España.

Durante los VIII Simposios de Ciencias Criptogámicas, Pangua, Prada y Salvo (1989) presentamos una comunicación en la que poníamos de manifiesto la existencia en la región levantina de Asplenium petrarchae (Guérin) DC subsp. bivalens (D.E. Meyer) Lovis y Reichst. y de A. majoricum Litard. Así mismo, observamos material en el que determinados caracteres se mostraban intermedios entre A. fontanum y $A$. petrarchae. Su contenido esporangial abortado, además, nos hacía aventurar que se trataba de un híbrido entre ambos táxones y que apuntábamos ya bajo la nomenclatura de A. x protomajoricum, todo ello en espera de la pertinente contrastación del análisis cromosómico. Los resultados del mismo llevado a cabo confirmaron las predicciones, remitiéndose para su publicación en marzo de 1991 al Botanical Journal of Linnean Society, siendo aceptado el 1 de mayo de 1991 y publicado en el volumen 108, de 1992.

Sorprendentemente días después de la aparición de nuestro artículo en el volumen 49(2) de los Anales del Jardín Botánico de Madrid aparecía un nuevo artículo, en esta ocasión firmado por Pérez-Carro y Fernández-Areces (1992), tan extraordinariamente similar que hasta el nothotaxon en cuestión es nombrado con el mismo epíteto.

En base a la aceptación, en sentido amplio, de la recomendación 30A del CINB no cabría duda que la combinación correcta a aplicar debía ser A. x protomajoricum Pangua y Prada. En cualquier caso, y con el fin de evitar ambiguiedades futuras, aplicamos el criterio del artículo 57 de dicho Código, reuniendo ambos táxones bajo el nombre de Asplenium x protomajoricum Pangua y Prada.

\section{BIBLIOGRAFÍA}

PANGUA, E., C. PRADA, S. PAJARÓN \& A.E. SALVO - 1992- A new Asplenium hybrid from Valencia (Spain) related to A. majoricum Litard. Bot.J. Linn. Soc., 108: 1-13. London.

PANGUA, E., C. PRADA y A.E. SALVO -1989-Contribución al conocimiento de Asplenium petrarchae (Guérin) DC in Lam. y DC y Asplenium majoricum Litard. en la Península Ibérica. VIII Simposios Ciencias Criptogámicas. Libro de Resúmenes. Melilla.

PÉREZ CARRO, F.J. y P. FERNÁNDEZ ARECES -1992- Asplenium x protomajoricum hybrid. nov. (A. fontanum subsp. fontanum x A. petrarchae subsp. bivalens) y precisiones corológicas sobre A. majoricum en el levante español. Anales Jard. Bot. Madrid, 49(2): 187-194. Madrid. 